\title{
Frequency of Multivessel Severe Coronary Artery Disease in Patients With Non-ST Segment Elevation Myocardial Infarction Having Markedly Raised Cardiac Troponin T
}

Kashif A. Hashmi ${ }^{1}$, Hadi Y. Saeed ${ }^{1}$, Muhammad Shahzad Farid ${ }^{1}$, Javeria Najam ${ }^{2}$, Muhammad Irfan ${ }^{3}$, Atif Ali Hashmi ${ }^{4}$

1. Cardiology, Chaudhry Pervaiz Elahi Institute of Cardiology, Multan, PAK 2. Medicine, Liaquat National Hospital and Medical College, Karachi, PAK 3. Statistics, Liaquat National Hospital and Medical College, Karachi, PAK 4. Pathology, Liaquat National Hospital and Medical College, Karachi, PAK

Corresponding author: Atif Ali Hashmi, atifhashmi345@gmail.com

\section{Abstract}

\section{Introduction}

Non-ST segment elevation myocardial infarction (NSTEMI) is becoming more common than ST segment elevation myocardial infarction (STEMI) and data regarding presence of underlying multivessel coronary artery disease (MVCAD) in these patients is consistent in locoregional population that leads to lethal delays in proper management. Therefore, in the current study, we aimed to evaluate the frequency of MVCAD in NSTEMI with markedly raised troponin $\mathrm{T}$ levels. This will help to identify patients that should be labeled as high risk and must be referred for coronary revascularization on priority basis, so that clinical outcomes can be improved in these patients.

\section{Methods}

This cross-sectional research study was carried out at Chaudhary Pervaiz Elahi Institute of Cardiology, Multan over a period of one year. A total of 326 patients with history of chest discomfort within past 48 hours of presentation or angina equivalent symptoms and cardiac troponin T more than $500 \mathrm{ng} / \mathrm{l}$ were included in the study. Coronary angiography was done within 72 hours of same hospital admission. The outcome variable i.e. MVCAD was determined.

\section{Results}

Mean age of patients was $50.74 \pm 7.75$ years with range of 30 to 60 years. MVCAD was found in 107 (32.82\%) patients, whilst there was no MVCAD in 219 (67.18\%) patients. Moreover, no significant association of MVCAD was noted with age or smoking.

Received 07/18/2020

Review began 07/22/2020 Review ended 07/22/2020 Published 08/05/2020

๑) Copyright 2020

Hashmi et al. This is an open access article distributed under the terms of the Creative Commons Attribution License CC-BY 4.0., which permits unrestricted use, distribution, and reproduction in any medium, provided the original author and source are credited.

\section{Conclusion}

We found presence of MVCAD in a considerable number of patients presenting with NSTEMI. The key to detect the underlying presence of MVCAD in these patients is lifted troponin T levels. Therefore, we conclude that any patient with elevated troponin T levels, even in the absence of ST segment elevation, should undergo cardiac catheterization to detect presence of MVCAD as this subset of patients can benefit from early revascularization including coronary artery bypass graft (CABG) surgery.

\section{Categories: Cardiology}

Keywords: multivessel coronary artery disease (mvcad), st segment elevation myocardial infarction (stemi), non-st segment elevation myocardial infarction (nstemi), acute coronary syndrome (acs), troponin t, unstable angina, myocardial infarction (mi)

\section{Introduction}

Myocardial infarction is the part of acute coronary syndrome (ACS) that includes unstable angina, non-STsegment elevation myocardial infarction (NSTEMI) and ST-segment elevation myocardial infarction (STEMI). Coronary artery disease is the leading killer of individuals worldwide and kills over 6 million individuals each year. NSTEMI is becoming more common than STEMI with the passage of time. The annual incidence is 73 per 1000 inhabitants, but differs among different countries with average hospital mortality rate of $3-5 \%[1-3]$.

Although STEMI is considered more dangerous as it reflects full thickness infarction of myometrial wall, there is now convincing evidence that NSTEMI may harbor a severe underlying disease in a significant number of cases. Over recent days, American College of Cardiology (ACC) and National Cardiovascular 
Database Registry (NCDR) outlined that $42 \%$ of NSTEMI patients had multi-vessel coronary artery disease (MVCAD) that requires an aggressive management approach [4]. MVCAD is defined by the presence of $\geqslant 50 \%$ diameter stenosis of two or more epicardial coronary arteries. The presence of MVCAD indicates poorer prognosis and a significantly higher mortality than single-vessel disease [5]. The affected arteries can be reopened using an angioplasty or rerouted using cardiac bypass surgery. In addition, thrombolysis may also lead to deceased frequency of left ventricular thrombus formation [6,7].

It is postulated that events underlying ACS, i.e. disruption or rupture of atherosclerotic plaque, are due to an underlying inflammatory process [8]. Cardiac troponin $\mathrm{T}$ is a component of contractile apparatus of cardiomyocytes and is preferred biochemical marker of myocardial infarction and necrosis in patients with NSTEMI. The testing for troponins is stipulated a major indication for early risk stratification according to ACC/American Heart Association (AHA) Guidelines, as it ameliorates the clinical outcomes in NSTEMI patients [9]. The outcome in patients with ACS is proportionate to the levels of serum troponin levels [10].

Although troponin $\mathrm{T}$ is considered as a marker of myocardial wall damage, data regarding its ability to predict the presence of underlying MVCAD is inconsistent in the locoregional population, a few studies reported an extensive CAD with only borderline troponin elevation [11,12], on the other hand studies have also shown a high frequency of MVCAD with NSTEMI with high troponin levels. Therefore, in the current study, we aimed to evaluate the frequency of MVCAD in NSTEMI with markedly raised troponin T levels. This will help to identify patients that should be labeled as high risk and must be referred for coronary revascularization on priority basis, so that clinical outcomes can be improved in these patients.

\section{Materials And Methods}

This cross-sectional research study was carried out at Chaudhary Pervaiz Elahi Institute of Cardiology, Multan over a period of one year. A total of 326 patients were enrolled. Patients of either gender, aged 30 years to 60 years that presented with chest pain or heaviness or other symptoms related to angina in the past two days along with cardiac troponin T more than $500 \mathrm{ng} / \mathrm{l}$ (normal value $<14 \mathrm{ng} / \mathrm{l}$ ) were included in the study. Patients with electrocardiogram (ECG) changes indicative of STEMI along with those whose ECG showed left bundle branch block or pathological $Q$ waves were excluded from the study. Patents with previous cardiac interventions or renal insufficiency (serum creatinine $>1.4 \mathrm{mg} / \mathrm{dl}$ ) and patients who denied to undergo coronary angiography during hospitalization were also excluded from the study.

Complete history and examination was done. Blood samples for cardiac troponin T were drawn after 8 hours and 48 hours of hospital admission. Troponin T was determined using COBAS ELECTROSYS 2010 ROCHE instrument. The troponin T more than $500 \mathrm{ng} / \mathrm{l}$ was labeled as markedly raised. Coronary angiography was done within 72 hours of same hospital admission. Coronary angiographic films were analyzed by a senior cardiologist having five-year post fellowship experience and lesion was assessed according to standard protocols. The outcome variable, i.e. MVCAD along with demographic profile, was entered in a pre-designed proforma and recorded.

\section{Statistical analysis}

Data was scrutinized by operating on statistical package for social sciences (SPSS) version 21 (IBM Corp., Armonk, NY). Mean and standard deviation were evaluated for quantitative variables while frequency and percentage were calibrated for qualitative variables. Stratification was done with reference to qualitative variables to see the effect of these modifiers on multi-vessel severe coronary artery disease by using chi square test. $\mathrm{p} \leqslant 0.05$ were considered as significant.

\section{Results}

Out of the 326 patients, 252 (77.30\%) were males and 74 (22.70\%) were females with ratio of 3.4:1. Mean age of patients was $50.74 \pm 7.75$ years with range of 30 to 60 years. Majority of the patients $(179,54.91 \%)$ were between 51 to 60 years of age. A total of 223 (68.4\%) patients of study population were smokers while ECG changes were found in 192 (58.9\%) patients. In our study, MVCAD was found in 107 (32.82\%) patients, whilst there was no MVCAD in 219 (67.18\%) patients. Detailed characteristics of study population are presented in Table 1 . 


\section{Cureus}

Characteristic

n (\%)

Gender

Male

252 (77.3)

Female

74 (22.7)

Age (years) ${ }^{\circ}$

$50.74 \pm 7.75$

Age Group

30-40 years

33 (10.1)

41-50 years

114 (35)

51-60 years

179 (54.9)

Smoker

Yes

223 (68.4)

No

103 (31.6)

ECG Changes

Yes

192 (58.9)

No

$134(41.1)$

Multi-vessel severe coronary artery disease

Present

107 (32.8)

Absent

219 (67.2)

\section{TABLE 1: Characteristics of study population}

${ }^{\circ}$ Mean \pm SD

When stratification was done on age groups reciprocal to MVCAD, it was recorded that there was no remarkable difference of MVCAD among different age groups $(\mathrm{p}=0.984)$ while gender stratification has also shown no statistically notable difference $(\mathrm{p}=0.630)$. Similarly, no significant association of MVCAD was noted with smoking status $(p=0.476)$ and ECG changes $(p=0.807)$. Detailed results of association are presented in Table 2 . 


\section{Cureus}

\begin{tabular}{|c|c|c|c|}
\hline & \multicolumn{2}{|c|}{ Multi-vessel severe coronary artery disease } & \multirow{2}{*}{ P-value } \\
\hline & Present $(n=107)$ & Absent $(n=219)$ & \\
\hline \multicolumn{4}{|l|}{ Gender } \\
\hline Male & $81(75.7)$ & $171(78.1)$ & \multirow{2}{*}{0.630} \\
\hline Female & $26(24.3)$ & $48(21.9)$ & \\
\hline \multicolumn{4}{|l|}{ Age Group } \\
\hline $30-40$ years & $11(10.3)$ & $22(10)$ & \multirow{3}{*}{0.984} \\
\hline $41-50$ years & $38(35.5)$ & $76(34.7)$ & \\
\hline $51-60$ years & $58(54.2)$ & $121(55.3)$ & \\
\hline \multicolumn{4}{|l|}{ Smoker } \\
\hline Yes & $76(71)$ & $147(67.1)$ & \multirow{2}{*}{0.476} \\
\hline No & 31 (29) & $72(32.9)$ & \\
\hline \multicolumn{4}{|c|}{ ECG Changes } \\
\hline Yes & $62(57.9)$ & $130(59.4)$ & \multirow{2}{*}{0.807} \\
\hline No & $45(42.1)$ & $89(40.6)$ & \\
\hline
\end{tabular}

\section{TABLE 2: Association of multi-vessel coronary artery disease with characteristics of study population}

Chi-Square test was applied.

$P$-value $\leq 0.05$, considered as significant.

\section{Discussion}

In the current study, we found out that a substantial number of patients with NSTEMI having markedly elevated troponin T levels had underlying MVCAD, that necessitated urgent revascularization including coronary artery bypass graft (CABG) surgery. Moreover, no significant association of MVCAD was noted with age or smoking.

According to severity, myocardial infarction can be branched into two types; NSTEMI is the less intrusive type. In NSTEMI, the blood clot partially blocks up the artery, and as a consequence only a section of the heart muscle being supplied by the influenced artery leads to ischemia. In contrary to the more intensified form of heart attack (STEMI), the NSTEMI does not account for attributable elevation in the "ST segment" portion of the ECG. Therefore, it signifies that in NSTEMI, the artery is not entirely occluded [10,13]. Considerable advances in the discernment of myocardial injury and necrosis have been made over the past few decades. Accordingly, the definition of MI has metamorphosed through the years.

A study demonstrated that patients with NSTEMI account for the majority (54\%) of acute MI patients admitted to the hospital. This study also revealed that patients with NSTEMI had higher one-year mortality (31\%) than patients with ST-elevation MI (21\%). Patients with NSTEMI tend to be older, have poorer LV function, multi-vessel disease and history of acute coronary events [14].

Age range in this study was 30 to 60 years with mean age of $50.74 \pm 7.75$ years with bulk of the patients i.e. 179 (54.91\%) were between 51 to 60 years of age. Compared to other regional studies our mean age was slightly lower that may correlate with the increasing trend of cardiovascular diseases in younger age groups [15]. Whether this is a true trend or just due to better investigative potential needs to be ascertained.

MVCAD was noted in 107 (32.82\%) patients, however there was no MVCAD in 219 (67.18\%) patients in our study. Altmann et al. in their study have shown the frequency of MVCAD in 54\% patients with NSTEMI [16]. Another study by Qadir et al., which included 230 NSTEMI patients, found that in 111 patients with cardiac troponin T levels $\leqslant 10$ folds upper limit of normal, 25 (22.52\%) had single vessel, 40 (36\%) had two vessel and 34 (30.6\%) had three vessel significant CAD, whereas in 119 patients with cardiac troponin $\mathrm{T}$ levels $>10$ folds upper limit of normal, 23 (19.3\%) had single vessel, 37 (31.1\%) had two vessel and 55 (46.2\%) had three 
vessel significant CAD [17]. Other studies reported frequency of MVCAD in NSTEMI ranging from 40 to $65 \%$ $[18,19]$, while a large ACC National Cardiovascular Database Registry report that included over hundred thousand patients, MVCAD was noted to be present in $42 \%$ of patients with NSTEMI [4]. Compared to these studies, frequency of MVCAD in our studied population was found to be slightly lower. This may be attributable to some different population characteristics in our study.

There exists some limitations to this study. Firstly, long-term follow-up was not done to detect mortality rates over a period of time. Secondly, this is a single institution data which may not be representative of entire population.

\section{Conclusions}

MVCAD was found to be present in a large number of patients that presented with NSTEMI along with elevated troponin levels in our study. Therefore, we recommend that every patient with elevated troponin levels despite absence of ST segment elevation in ECG should have cardiac catheterization to evaluate the presence of underlying MVCAD. Early detection of MVCAD in these patients may lead to improved patient outcomes.

\section{Additional Information \\ Disclosures}

Human subjects: Consent was obtained by all participants in this study. Ch. Pervaiz Elahi Institute of Cardiology, Multan issued approval CPEIC-039-2020. The approval for the study was taken from Department of Academic Affairs, Ch. Pervaiz Elahi Institute of Cardiology, Multan. Animal subjects: All authors have confirmed that this study did not involve animal subjects or tissue. Conflicts of interest: In compliance with the ICMJE uniform disclosure form, all authors declare the following: Payment/services info: All authors have declared that no financial support was received from any organization for the submitted work. Financial relationships: All authors have declared that they have no financial relationships at present or within the previous three years with any organizations that might have an interest in the submitted work. Other relationships: All authors have declared that there are no other relationships or activities that could appear to have influenced the submitted work.

\section{References}

1. Fox KA, Eagle KA, Gore JM, Steg PG, Anderson FA; GRACE and GRACE Investigators: The global registry of acute coronary events, 1999 to 2009--GRACE. Heart. 2010, 96:1095-1101. 10.1136/hrt.2009.190827

2. Yeh RW, Sidney S, Chandra M, Sorel M, Selby JV, Go AS: Population trends in the incidence and outcomes of acute myocardial infarction. N Engl J Med. 2010, 362:2155-2165. 10.1056/NEJMoa0908610

3. Hashmi KA, Abbas K, Hashmi AA, Irfan M, Edhi MM, Ali N, Khan A: In-hospital mortality of patients with cardiogenic shock after acute myocardial infarction; impact of early revascularization. BMC Res Notes. 2018, 11:721. 10.1186/s13104-018-3830-7

4. Brener SI, Milford-Beland S, Roe MT, Bhatt DL, Weintraub WS, Brindis RG: Culprit-only or multivessel revascularization in patients with acute coronary syndromes: an American College of Cardiology National Cardiovascular Database Registry report. Am Heart J. 2008, 155:140-146. 10.1016/j.ahj.2007.09.007

5. O'Keefe JH Jr, Rutherford BD, McConahay DR, et al.: Multivessel coronary angioplasty from 1980 to 1989: procedural results and long-term outcome. J Am Coll Cardiol. 1990, 16:1097-1102. 10.1016/07351097(90)90538-z

6. Rodriguez A, Bernardi V, Navia J, et al.: Argentine randomized study: coronary angioplasty with stenting versus coronary bypass surgery in patients with multiple-vessel disease (ERACI II): 30-day and one-year follow-up results. J Am Coll Cardiol. 2001, 37:51-58. 10.1016/s0735-1097(00)01052-4

7. Hashmi KA, Saeed HY, Ahmed J, Najam J, Irfan M, Hashmi AA: Left ventricular thrombus formation in acute anterior wall myocardial infarction: a comparison between thrombolyzed and non-thrombolyzed patients. Cureus. 2020, 12:9090. 10.7759/cureus.9090

8. Asakura M, Ueda Y, Yamaguchi O, Adachi T, Hirayama A, Hori M, Kodama K: Extensive development of vulnerable plaques as a pan-coronary process in patients with myocardial infarction: an angioscopic study. J Am Coll Cardiol. 2001, 37:1284-1288. 10.1016/s0735-1097(01)01135-4

9. Anderson JL, Adams CD, Antman EM, et al.: ACC/AHA 2007 guidelines for the management of patients with unstable angina/non-ST-elevation myocardial infarction: a report of the American College of Cardiology/American Heart Association Task Force on Practice Guidelines (Writing Committee to Revise the 2002 Guidelines for the Management of Patients With Unstable Angina/Non-ST-Elevation Myocardial Infarction) developed in collaboration with the American College of Emergency Physicians, the Society for Cardiovascular Angiography and Interventions, and the Society of Thoracic Surgeons endorsed by the American Association of Cardiovascular and Pulmonary Rehabilitation and the Society for Academic Emergency Medicine. J Am Coll Cardiol. 2007, 50:1-157. 10.1016/j.jacc.2007.02.013

10. Ottani F, Galvani M, Nicolini FA, Ferrini D, Pozzati A, Di Pasquale G, Jaffe AS: Elevated cardiac troponin levels predict the risk of adverse outcome in patients with acute coronary syndromes. Am Heart J. 2000, 140:917-927. 10.1067/mhj.2000.111107

11. Henrikson CA, Howell EE, Bush DE, et al.: Prognostic usefulness of marginal troponin T elevation . Am J Cardiol. 2004, 93:275-279. 10.1016/j.amjcard.2003.10.004

12. Sabatine MS, Morrow DA, McCabe CH, Antman EM, Gibson CM, Cannon CP: Combination of quantitative ST deviation and troponin elevation provides independent prognostic and therapeutic information in unstable 


\section{Cureus}

angina and non-ST-elevation myocardial infarction. Am Heart J. 2006, 151:25-31. 10.1016/j.ahj.2005.02.030

13. Hashmi KA, Shehzad A, Hashmi AA, Khan A: Atrioventricular block after acute myocardial infarction and its association with other clinical parameters in Pakistani patients: an institutional perspective. BMC Res Notes. 2018, 11:329. 10.1186/s13104-018-3431-5

14. O'Neil BJ, Hoekstra J, Pride YB, et al.: Incremental benefit of 80-lead electrocardiogram body surface mapping over the 12-lead electrocardiogram in the detection of acute coronary syndromes in patients without ST-elevation myocardial infarction: results from the Optimal Cardiovascular Diagnostic Evaluation Enabling Faster Treatment of Myocardial Infarction (OCCULT MI) trial. Acad Emerg Med. 2010, 17:932-939. 10.1111/j.1553-2712.2010.00848.x

15. Lakhani MS, Qadir F, Hanif B, Farooq S, Khan M: Correlation of thrombolysis in myocardial infarction (TIMI) risk score with extent of coronary artery disease in patients with acute coronary syndrome. J Pak Med Assoc. 2010, 60:197-200.

16. Altmann DR, Mutschelknauss M, Ehl N, et al.: Prevalence of severely impaired left ventricular ejection fraction after reperfused ST-elevation myocardial infarction. Swiss Med Wkly. 2013, 143:13869.

10.4414/smw.2013.13869

17. Qadir F, Farooq S, Khan M, Hanif B, Lakhani MS: Correlation of cardiac troponin I levels (10 folds upper limit of normal) and extent of coronary artery disease in non-ST elevation myocardial infarction. J Pak Med Assoc. 2010, 60:423-428.

18. Isilak Z, Kardesoglu E, Aparci M, et al.: Comparison of clinical risk assessment systems in predicting threevessel coronary artery disease and angiographic culprit lesion in patients with non-ST segment elevated myocardial infarction/unstable angina pectoris. Kardiol Pol. 2012, 70:242-250.

19. Moses J, Doubell AF, Herbst PG, Klusmann KJ, Weich HS: Non-ST elevation myocardial infarction (NSTEMI) in three hospital settings in South Africa: does geography influence management and outcome? A retrospective cohort study. Cardiovasc J Afr. 2013, 24:110-116. 10.5830/CVJA-2013-017 